
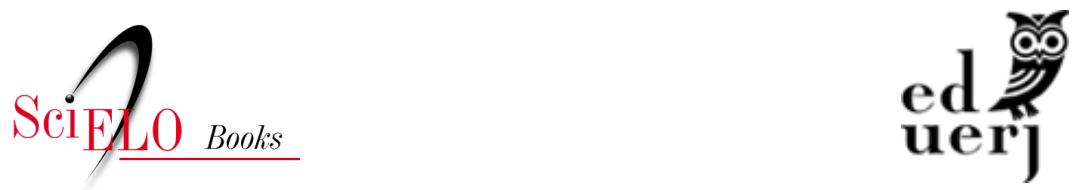

\title{
PMCMV e produção imobiliária nas cidades de Patos e Cajazeiras/PB
}

\author{
Luciana Medeiros de Araújo
}

\section{SciELO Books / SciELO Livros / SciELO Libros}

ARAÚJO, L. M. PMCMV e produção imobiliária nas cidades de Patos e Cajazeiras/PB. In.: MAIA, D. S., and MARAFON, G. J., eds. O programa Minha Casa Minha Vida: habitação e produção do espaço urbano em diferentes escalas e perspectivas [online]. Rio de Janeiro: EDUERJ, 2020, pp. 189-213. ISBN: 978-65-00-03029-7. https://doi.org/10.7476/9786500030297.0008.

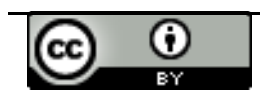

All the contents of this work, except where otherwise noted, is licensed under a Creative Commons Attribution 4.0 International license.

Todo o conteúdo deste trabalho, exceto quando houver ressalva, é publicado sob a licença Creative Commons Atribição 4.0.

Todo el contenido de esta obra, excepto donde se indique lo contrario, está bajo licencia de la licencia Creative Commons Reconocimento 4.0. 


\section{PMCMV e produçáo imobiliária nas cidades de Patos e Cajazeiras/PB}

Luciana Medeiros de Araújo

O presente capítulo apresenta alguns resultados da pesquisa doutoral sobre a produçáo imobiliária e a expansão urbana das cidades de Patos e de Cajazeiras, situadas na mesorregião do Sertão Paraibano, às margens da BR230. Conforme a recente Divisão Urbano Regional (IBGE, 2013), cada uma dessas cidades compóe Regiôes Intermediárias de Articulação Urbana, cujas áreas de influência territorial extrapolam os limites definidos por suas microrregiôes geográficas e os limites estaduais.

A delimitação territorial das duas regióes intermediárias abrange 56 municípios, o que equivale a $25 \%$ do total existente no estado, chegando a mais de 60\% dos municípios do Sertáo Paraibano. Entre os anos de 2009 e 2015, Patos e Cajazeiras se destacaram entre as cidades interioranas pela grande abertura de loteamentos residenciais e pela produção habitacional financiada pelo Programa Minha Casa Minha Vida (PMCMV), instituído em 2009 pelo governo federal, no governo do presidente Luiz Inácio Lula da Silva (2003-11).

Em âmbito nacional, esse programa reafirmou o imprescindível lugar do Estado como propulsor da promoção imobiliária voltada à habitação de interesse social, bem como à de mercado. Igualmente redefiniu as diretrizes de subvenção de crédito habitacional para famílias de baixa renda e garantiu o crédito imobiliário a empresas de construção para a promoção privada de habitação de mercado, com abrangência de segmentos da população de médio e alto rendimento. Assim, as açóes do Estado propiciaram grande impulso à economia urbana, à mobilidade do capital e, por conseguinte, à convergência de agentes imobiliários privados locais e não locais, em especial 
incorporadores e construtoras, com capacidade de investir, intervir e transformar o setor imobiliário e o espaço urbano.

O presente texto aporta-se em referenciais teórico-metodológicos relativos à produção capitalista do espaço urbano, com ênfase na produção da habitação de interesse social pelo PMCMV. A coleta de dados primários e secundários, bem como os trabalhos de campo foram realizados no decorrer da pesquisa doutoral (2013-16). Os dados primários foram arrolados a partir da análise dos processos de incorporaçóes dos empreendimentos imobiliários, disponibilizados para consulta nos cartórios de registros de imóveis das cidades investigadas; e os secundários obtivemos por meio do acesso a sites oficiais e a demandas enviadas às instituiçóes nacionais, estaduais e municipais pelo Serviço Eletrônico de Informação ao Cidadão (e-SIC) e Formulário de Acesso à Informação, disponíveis na internet. Dentre essas instituiçôes, estáo a Secretaria Nacional de Habitação, o Ministério das Cidades, o Instituto Brasileiro de Geografia e Estatística (IBGE), a Fundação João Pinheiro, o Conselho Regional de Engenharia e Agronomia (CREA/PB) e as prefeituras municipais. Nos trabalhos de campo, realizamos registros fotográficos, entrevistas semiestruturadas e conversas informais. Os dados sistematizados estão representados em gráficos, tabelas e imagens do Google Earth.

\section{Notas introdutórias sobre o PMCMV}

Desde a sua instituição, o PMCMV objetiva criar mecanismos de incentivo à construção e à aquisição de novas habitaçôes por famílias com rendimento bruto de até dez salários mínimos, discriminadas por diferentes faixas de renda familiar - Faixa 1 (até 3 salários mínimos), Faixa 2 (de 3 a 6 salários mínimos) e Faixa 3 (até 10 salários mínimos ). ${ }^{11}$ A meta inicial do programa estabeleceu a produção de um milhão de moradias para todo o território nacional, sendo $40 \%$ desse total para as famílias com renda de até três salários, portanto, inseridas na Faixa 1. Para esta faixa, os beneficiários devem

1 No final de 2016, o governo Temer inverteu as metas de produção por faixa, favorecendo a produçáo da habitaçáo de mercado. Foi aumentado o limite de renda em todas as faixas, principalmente, na Faixa 3, que passou de 6,5 para 9 mil reais. Ampliou-se o limite do uso do FGTS, bem como o teto dos preços dos imóveis. Nesse contexto, das 610 mil unidades previstas para contratação, apenas 27,8\% (170 mil) foram destinadas para a Faixa 1; 6,5\% (40 mil), para a Faixa 1,5 (nova faixa criada); e 65,5\% (400 mil) para as Faixas 2 e 3, cujo rendimento pode variar de 4 a 9 nove mil reais 
ser cadastrados pelas prefeituras, na Secretaria de Desenvolvimento Humano, e a habitação é subsidiada, quase totalmente, pelo governo federal, com um comprometimento de, no máximo, $5 \%$ da renda familiar, ${ }^{22}$ ou seja, a aquisição é feita fora do crédito hipotecário (Shimbo, 2010 e Rolnik, 2015).

No contexto de sua implantação, o PMCMV foi revestido como a "mais importante ação no campo econômico-social, articulando a oferta de moradia, demanda histórica e ativo eleitoral tradicionalmente forte, com uma estratégia keynesiana de crescimento econômico e geração de empregos”, segundo Rolnik (2015, p. 301). Nesse sentido, ante esse apelo e essas expectativas, o programa foi articulado como base em três campos de ação: o social, o econômico e o político.

Em linhas gerais, o PMCMV teria que, socialmente, garantir o acesso à casa própria para um crescente número de famílias de diferentes segmentos de renda; isto é, reduzir o déficit habitacional dos segmentos mais pobres, bem como atender à grande demanda social por habitação das famílias de médio rendimento, retida desde os anos 1990. Para isso, o governo federal ampliou as estratégias de aquisição de moradia, por meio da liberação de subsídio, associado ou não à concessão de crédito.

Economicamente, foi necessário impulsionar o crescimento da economia e a geração de emprego e aquecer o setor imobiliário, notadamente a construção civil e a comercialização de habitação de mercado. Segundo o Balanço do PAC (2015), entre 2009 e 2013 foi criada, por ano, uma média de 921 mil empregos diretos e indiretos na construção civil. Como especificado em relatório, "calcula-se, ainda, que, para cada $\mathrm{R} \$ 1$ milhão desembolsado pelo programa, outros $\mathrm{R} \$ 744$ mil são gerados em renda, com impacto direto no consumo e repercussão em diversas outras cadeias produtivas da economia" (PAC, 2015, p. 45).

Do ponto de vista político, para garantir mais apoio da base dos movimentos sociais de luta pela moradia, o governo definiu linhas de crédito associativo vinculado às entidades, bem como para as famílias do campo, além de estender o programa aos municípios com população inferior a 50

2 Conforme o site do Portal Minha Casa Minha Vida, as recentes mudanças nos limites de renda familiar para efeito de financiamento, em 2016, não alteram a Faixa 1. Contudo, as prestaçóes passaram a ser pagas em até 120 meses, sem juros, com comprometimento máximo de $28 \%$ da renda familiar. Os subsídios podem chegar até $90 \%$ do valor do imóvel. 
mil habitantes. Porém, é no âmbito econômico que o PMCMV está efetivamente assentado. Como admite Rolnik (2015), desde a criação do programa, o PMCMV-Empresas passou a constituir o "núcleo duro" da atual PNH.

Nessa modalidade, a empresa de construção civil apresenta o projeto do empreendimento à instituição financeira - CEF ou Banco do Brasil - que, depois de analisar a viabilidade, contrata a operação e acompanha a execução da obra. Concluída a obra, a instituição financeira gestora responsabiliza-se pela alienação das unidades para as famílias selecionadas. Nesse caso, o PMCMV prevê o limite de trezentas unidades habitacionais por projeto. Entretanto, é frequente a inobservância dessa norma, a exemplo da contratação do Residencial Itatiunga, em Patos, feita com 770 unidades edificadas na Faixa 1, operacionalizadas pelo Banco do Brasil, em parceria com os governos municipal e estadual.

No âmbito do Brasil, ao tomarmos como referência o recorte temporal 2009-15, a análise dos relatórios de produção habitacional do PMCMV (SNH/MCIDADES, 2016) revelou que, na primeira etapa, o PMCMV 1 atingiu a meta, consolidando-se para a implementação da segunda etapa. Nesta, o total de unidades contratadas em todo o país chegou a mais de 2,7 milhóes de unidades, sendo mais de $40 \%$ desse total destinado a famílias de baixa renda.

Nas duas primeiras etapas, somente na Faixa 1, foram edificadas mais de 1,7 milhão de habitaçóes, importando uma contratação média superior a trezentas mil unidades por ano. Um volume que foi bastante desacelerado na terceira etapa do programa, a partir de 2015. Todavia, certificamos que a produçáo habitacional dentro da linha de financiamento da Faixa 2 teve contrataçóes sempre crescentes, superando o total de unidades contratadas naquela faixa. Vejamos os dados sistematizados na tabela 1 : 
Tabela 1 -. Brasil: Unidades habitacionais contratadas por faixa e por etapa do PMCMV - 2009 a 2015

\begin{tabular}{|c|c|c|c|c|c|c|c|c|}
\hline \multirow[b]{2}{*}{ FAIXAS } & \multicolumn{6}{|c|}{ ETAPAS DO PMCMV } & \multicolumn{2}{|c|}{ Total por faixa } \\
\hline & $\begin{array}{c}\text { PMCMV } 1 \\
(2009-10)\end{array}$ & $(\%)$ & $\begin{array}{c}\text { PMCMV } 2 \\
(2011-14)\end{array}$ & $(\%)$ & $\begin{array}{c}\text { PMCMV } 3 \\
(2015) \\
\end{array}$ & $(\%)$ & Absoluto & $(\%)$ \\
\hline Faixa 1 & 482.741 & 48,0 & 1.226 .605 & 44,6 & 16.890 & 4,1 & 1.726 .236 & 41,4 \\
\hline Faixa 2 & 375.764 & 37,3 & 1.216 .341 & 44,2 & 349.604 & 85,8 & 1.941 .709 & 46,6 \\
\hline Faixa 3 & 146.623 & 14,5 & 307.054 & 11,1 & 40.557 & 9,9 & 464.234 & 11,2 \\
\hline Total/Etapa & 1.005 .128 & 100 & 2.750 .000 & 100 & 407.051 & 100 & 4.162 .179 & 100 \\
\hline
\end{tabular}

Fonte: Elaborada por Luciana M. de Araújo (2017), a partir de relatórios da SNH/MCIDADES (2016).

Como já observado, para as Faixas 2 e 3, os limites de rendimento familiar para o financiamento variam de três a dez salários mínimos. Essas faixas concentram as contrataçóes financiadas com recursos do FGTS, contraídas diretamente pelo comprador nas instituiçóes financeiras autorizadas pelo Banco Central. Em ambas, os financiamentos incluem as taxas de juros, que podem chegar a $8 \%$ ao ano, segundo informativos da CEF. Porém, como demonstrado no overview do PMCMV, o funcionamento operacional é diferenciado.

Para a Faixa 2, o governo garante dois tipos de subsísdios. Um é complementar, com aporte financeiro direto, variando em função da renda, da modalidade e da unidade federativa; o outro é definido como de equilíbrio, pois visa reduzir a taxa de juros do financiamento. Além destes, é disponibilizado o acesso ao Fundo Garantidor da Habitaçáo (FGHab), usado para reduzir custos de seguro e refinanciar parte das prestaçóes em caso de perda da renda ou de desemprego. Esse fundo é destinado também para financiamentos na Faixa 3.

Conforme o Ministério das Cidades (2012), para assegurar a compatibilização do pagamento das prestaçóes com a renda familiar, o PMCMV estabeleceu diretrizes, tais como: o pagamento da primeira prestação a partir da entrega do imóvel; nos casos de financiamento, pagamento opcional de entrada; a redução do risco do financiamento com o Fundo Garantidor; ${ }^{3}$

3 Segundo o Ministério das Cidades, o Fundo Garantidor tem aporte em recursos da União para garantir o refinanciamento de parte das prestaçóes em caso de perda da renda, estabelecendo a cobertura para o período de vigência do contrato. 
o barateamento do seguro; e a desoneração fiscal e de custos cartoriais. Essas diretrizes tornaram o PMCMV uma política pública que toma o Estado como agente impulsionador da expansão da produção imobiliária no país (Maricato, 2015).

Para as Faixas 2 e 3, tanto a construção quanto a comercialização da habitação são feitas de modo direto via construtora ou construtor, na forma de pessoa jurídica e/ou física. Como Rolnik (2015, p. 304) reforça, “a Caixa [CEF] financia a produção e fornece subsídios para quem quiser comprar as unidades, mas os riscos e as responsabilidades são assumidos pela empresa”. Para controlar as construtoras, as instituiçóes financeiras e garantir os subsídios, é o programa que define o preço máximo da habitação a ser adquirida, segundo a unidade federativa e a localidade para a execução das obras.

Em um ano, correspondente à terceira etapa do programa - o PMCMV 3 -, a produção habitacional pela Faixa 2 atingiu um percentual que superou $80 \%$ do total das novas unidades contratadas. Uma quantidade de contratos efetivados díspar do verificado na Faixa 1, inferior a 5\%. Segundo Rolnik (2015), houve um deslocamento das empresas incorporadoras que atuaram na Faixa 1, na primeira etapa do programa, e quando conseguiram grandes lucros, voltaram para seus antigos nichos de mercado, ou seja, para as faixas de mais capacidade de solvência.

Ao nosso ver, essa é uma tendência ratificadora do viés empresarial do programa, distanciando-o de suas diretrizes iniciais de priorizar a política habitacional de interesse social. Náo resta dúvida de que com o PMCMV o setor imobiliário foi extremamente contemplado pela interposição do Estado. Nas palavras de Fix (2011, p. 26), a atual PNH, alargou o espaço do circuito imobiliário em vários sentidos, aumentando a capacidade de circulação e de acumulação de capital, por meio da produção habitacional.

De modo efetivo, as novas diretrizes da Política Nacional de Habitação (BNH) impulsionaram a mobilidade do capital imobiliário também para as cidades de porte médio, sobretudo para as que exercem mais centralidade socioeconômica em suas regióes de influência urbana, imediata e intermediária (IBGE, 2013). É nesse contexto que a produção imobiliária em Patos e em Cajazeiras assume dimensão considerável na dinâmica de expansão territorial e de circulação de capitais.

Segundo registrado no próximo gráfico (n. ${ }^{\circ}$ 1), nos seis anos de intervalo investigados pela pesquisa (2009-15), as novas unidades habitacionais 
contratadas pelo PMCMV totalizaram 1.635 em Cajazeiras e 2.772 em Patos (SHN/MCIDADES, 2016). Nessas cidades, os financiamentos habitacionais instrumentalizados pelo Sistema Nacional Habitação de Interesse Social (SNHIS) somaram um número maior nas faixas contratadas com recursos do Fundo de Garantia por Tempo de Serviço (FGTS). A considerar as dimensões populacionais nessas localidades, houve um equilíbrio no número de contrataçóes realizadas por meio desses recursos, o que evidencia a existência de uma demanda retida por parte das famílias com rendimento acima de três salários mínimos.

Gráfico 1 - Total de unidades habitacionais contratadas pelo PMCMV, por origem de recursos, em Patos e Cajazeiras/PB - 2009 a 2015

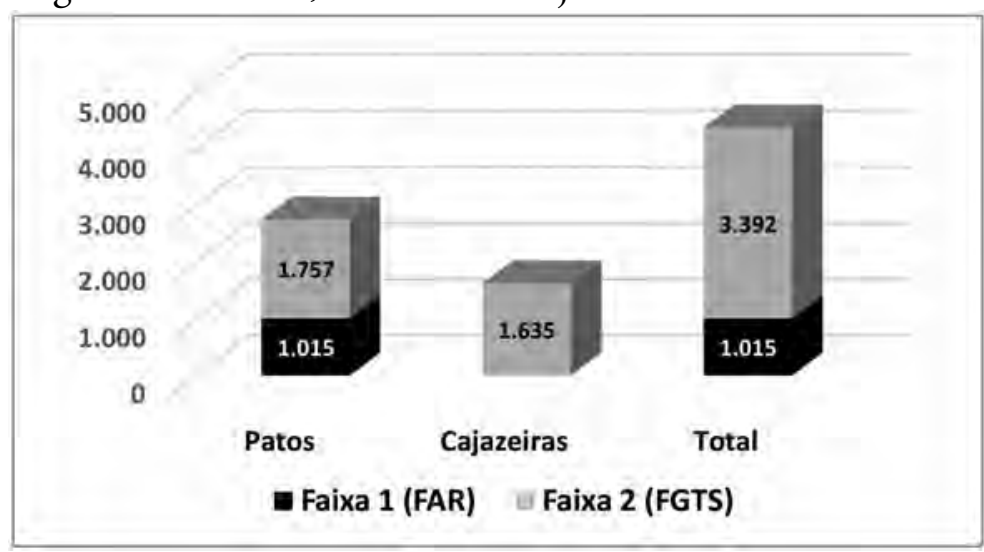

Fonte: Elaborado por Luciana M. de Araújo (2017), a partir de relatórios da SNH/MCIDADES (2016).

O gráfico evidencia também que apenas em Patos foram produzidas habitaçóes na Faixa 1, com subvenção do Fundo de Arrendamento Residencial (FAR). O percentual de unidades habitacionais produzidas nessa faixa de rendimento, entre 2009 e 2015 , correspondeu a 23\% do total de unidades. Em Cajazeiras, como a produção atendeu somente ao segmento de renda enquadrado nas Faixas 2 e 3, os financiamentos realizados via FGTS constituíram a totalidade da produção habitacional contratada pelo PMCMV.

Salientamos que, nesta breve análise, os dados consultados referentes ao PMCMV não incluem a contratação de financiamento habitacional pelo Sistema Brasileiro de Poupança e Empréstimo (SBPE), vinculada ou não ao 
Sistema Financeiro de Habitação. ${ }^{4}$ Esses financiamentos são realizados diretamente com o construtor, contratados por famílias com rendimento acima de dez salários mínimos, portanto, fora das linhas de rendimento previstas pelo programa e sem limites máximos prefixados.

A par dos dados relativos à recente produção habitacional vinculada apenas ao PMCMV, depreendemos que esses percentuais devem ser melhor avaliados pela gestão local para fins de elaboração de políticas urbanas. Com efeito, a manutenção do ritmo acelerado dessa produção tem exercido mais pressão sobre o Estado, em diferentes esferas públicas, no que diz respeito à necessidade de implantar e/ou ampliar equipamentos de infraestrutura básica, bem como as de uso coletivo, como escolas, creches e postos de saúde.

Igualmente, reafirmamos o lugar de destaque dos construtores e dos promotores imobiliários de capital não local como agentes propulsores do processo de expansão territorial das cidades de Patos e de Cajazeiras. Os memoriais de incorporação dos empreendimentos contratados pelo FAR, em Patos, registram que foram incorporados por empresas com sede em João Pessoa: o Residencial Itatiunga, incorporado pela BW Construção e Imobiliária Ltda., com execução das obras pela CRE Engenharia Ltda. O Vista da Serra I e II foram incorporados e construídos pela JGA Engenharia Ltda. em parceria com a CEHAP-PB.

Independente da origem do capital investido na promoção imobiliária e do empreendimento ser destinado à construção de habitação popular, o processo de promoção imobiliária, atinente à realizaçáo de suas etapas, não se diferencia. Comumente, o rito desse processo se assemelha e se reproduz como uma prática da produção da habitação em diferentes escalas territoriais e para distintas finalidades de consumo da mercadoria produzida: a habitação.

De modo sucinto, o passo inicial para transcorrer a incorporação é a aquisição da gleba rural, que, em geral, é desmembrada de uma propriedade rural periurbana. Como sequenciado por Topalov (1979b, s/p.), adquirida a terra, o promotor "acude a un arquitecto o va a una oficina de estudios para

${ }_{4}^{4}$ Apesar de o governo federal não subvencionar créditos imobiliários diretos para os financiamentos realizados pelo SFH, com recursos do SBPE, os contratos firmados apresentam condições diferenciadas em relação às contraçóes instrumentalizadas pelo SFI, a exemplo do uso do FGTS. Quando os financiamentos são requeridos nesse último sistema, os recursos são oriundos do mercado de capitais, tais como: fundos de pensóes, fundos de renda fixa e bancos de investimentos (Fix, 2011), cujas taxas de juros são reguladas pelo Banco Central. 
transformar esse programa en proyecto, y acude a empresas para construir los edifícios”. Portanto, além da aquisição da terra, em geral o construtor terá que recorrer à busca de capital para a execução do seu projeto.

No âmbito do ciclo de reprodução do capital investido na produção e na circulação de habitações, essa busca é indispensável à execução do projeto e à realizaçáo do lucro. Como assinala aquele mesmo autor (1979), o período de rotaçáo do capital é longo, principalmente no que refere ao período de produção, o qual corresponde ao processo de trabalho necessário para se executar a obra até a entrega da unidade habitacional produzida.

De modo particular, esse é um processo lento, cuja duração depende da existência da concentração anterior de capital da empresa, em especial, "de um capital de giro que garanta o retorno à forma de dinheiro do capital produtivo antes do final do período de produção, isto é, uma rotação normal do capital industrial [partes de capital investido nas construtoras, por exemplo, o capital produtivo]" (Topalov, 1979, pp. 54-5). Significa, assim, a existência de condiçôes financeiras para o pré-financiamento da obra.

No caso das construtoras selecionadas, aptas a executarem obras operacionalizadas pelo PMCMV, no "pacote" contratual inclui-se o capital de promoção, viabilizado pela instituição financeira pública gestora e fiscalizadora do projeto. Ou seja, isenta a empresa de disponibilizar imediatamente seu capital de giro, que é pré-condição para a realização da obra. Esse capital vai intervir no curso e no tempo do período de produçáo, reduzindo-o, por exemplo. Portanto, inserida nos termos contratuais de adesão ao programa, a construtora garante, com antecipação, o capital necessário para se construir habitação e prevê seus lucros, a considerar que o valor da unidade habitacional é previamente contratado, definido por normativas elaboradas pelo Ministério das Cidades por meio de portaria. ${ }^{5}$

Feitas essas breves consideraçóes sobre o PMCMV, a seguir apresentaremos os dois empreendimentos contratados pelo FAR em Patos.

\footnotetext{
5 Segundo a Portaria no 168/2013, do Ministério das Cidades, "os valores máximos de aquisição estabelecidos [...] poderão compreender os custos de aquisição do terreno, edificação, equipamentos de uso comum, tributos, despesas de legalização, trabalho social e execução de infraestrutura interna, excetuada a de responsabilidade da distribuidora de energia elétrica”.
} 


\section{Caracterização dos empreendimentos imobiliários contratados com recursos do FAR na cidade de Patos/PB}

O Residencial Itatiunga, contratado em 2012 por meio de parceria entre os governos federal, estadual e municipal, é o conjunto com o maior número de unidades habitacionais construído pelo PMCMV no sertáo paraibano. ${ }^{6}$ Esse empreendimento começou com a formação da Empresa BW Construção e Imobiliária $\mathrm{Ltda}^{7}$, seguido do processo de incorporação do loteamento, com a compra do terreno.

Em consulta ao site consultasocio.com, ${ }^{8}$ sobre sociedades empresariais no Brasil, apuramos que os sócios administradores daquela empresa estão vinculados a outras atividades econômicas distintas das que compóem o setor imobiliário (compra, venda e construçâo de imóveis). Conforme consta nesse site e no da Receita Federal, um dos sócios incorporadores do Loteamento Itatiunga possui empresas de comércio varejista de alimentos associado à rede de Supermercados Bemais, localizada em João Pessoa, e de produção de eventos de vaquejadas e rodeios em Sáo Miguel de Taipu (PB). O outro sócio tem atividades relacionadas à comunicação e à radiofonia, com sede em Catolé do Rocha $(\mathrm{PB})$.

Isso ratifica a mobilidade social e espacial de distintas fraçóes do capital para o setor imobiliário e reafirma as reflexóes de Cano (2010) sobre a particularidade especulativa e rentista de fraçôes de capital mercantil investido nesse setor, especialmente nas atividades de incorporação e de construção civil. Esse capital, ao convergir para a produção imobiliária, tende a dominar o processo de expansão territorial da cidade, bem como a "administração privada de negócios públicos” (Cano, 2010), a exemplo da incorporação de conjuntos habitacionais a serem operacionalizados pelo PMCMV.

6 Em Sousa, no Sertão Paraibano, o PMCMV operacionalizou a construção de 726 unidades habitacionais, financiadas com recursos do FAR e já entregues: o Residencial Lagoa dos Patos, com 274 unidades, contratado em 2010, com valor de 10 milhóes de reais; e o Residencial de Sousa, com 452 unidades, contratado pelo valor de 21,6 milhóes de reais, em 2012.

7 A empresa está inscrita no CNAE e sua atividade principal é a corretagem para compra, venda e avaliação de imóveis. Porém, o quadro de atividades secundárias é bastante diversificado e inclui a construção de edifícios e de obras de urbanização, terraplanagens e de incorporaçóes etc.

8 Site de cadastro de empresas e sócios de empresas brasileiras, com busca a partir do nome. Disponível em: https://www.consultasocio.com/. 
O Residencial Itatiunga faz parte do loteamento de mesmo nome, localizado no Bairro Morada do Sol, às margens da BR-361, Km 7, saída para Piancó, no setor oeste da cidade de Patos. A certidão vintenária presente no memorial de incorporação atesta que as terras rurais que abrigam o loteamento pertenciam à Fazenda Várzea da Jurema, cuja área total era de 745,3ha.

Essa propriedade foi por várias vezes desmembrada em glebas para o parcelamento em lotes urbanizados, cujos loteamentos originaram os conjuntos habitacionais Bivar Olyntho (1982), com 30ha, e o Pró-Moradia (2008), com 5,6ha, construídos pela CEHAP-PB. Em 2011 e 2012 foram implantados dois loteamentos: o Antônio David Lima I e o II, que somam uma dimensão de 6,8ha, além do Itatiunga, já referido, com 61,4ha. Ou seja, 103,8 ha, cerca de $14 \%$ das terras daquela propriedade, foram transformados em lotes urbanizados, agregados à malha urbana consolidada. Em termos de lotes, foram abertos 2.699 lotes, dos quais 770 , inseridos nesse último loteamento, voltados à construçóes do PMCMV.

A incorporação do Residencial Itatiunga compreende uma área de $614.992,00 \mathrm{~m}^{2}(61,4 \mathrm{ha})$, e a área dos lotes mede $343.528,19 \mathrm{~m}^{2}$, ou seja, cerca de 55\% do total loteado. Respaldado pela Portaria n. ${ }^{\circ}$ 168/2013 do Ministério das Cidades, o projeto arquitetônico foi executado em duas etapas: uma relativa à implantação do Residencial Itatiunga, outra, ao Loteamento Parque Itatiunga, compreendendo 954 lotes comercializáveis.

Consoante à referida portaria, quando o projeto do empreendimento é apresentado para que se executem as obras em mais de uma etapa, este é identificado como único. Entretanto, é necessário que seja "considerado contíguo a outro quando a menor distância, em linha reta, do ponto do perímetro da sua poligonal mais próximo ao perímetro da poligonal do outro empreendimento for igual ou inferior a 1.000 (um mil) metros" (MCidades, 2013).

No que concerne à contiguidade, o projeto daquele residencial encontra-se adequado à portaria. Contudo, há inadequação quanto à feitura em duas etapas no que diz respeito ao número mínimo de mil unidades habitacionais por etapa. Igualmente, a portaria estabelece o máximo de doze meses entre cada etapa, porém, apenas uma foi entregue, e com dois anos de atraso.

Apesar do loteamento ter sido incorporado como um projeto único, no decorrer de sua implantação ele assumiu duas finalidades distintas: a construção de HIS, vinculada ao PMCMV, e a comercialização privada dos lotes. A 
parte comercializada terminou por corresponder à segunda etapa do Projeto Residencial Itatiunga, como pode ser observado nas figuras 1 e 2 .

Figura 1 - Outdoor do Residencial Itatiunga, financiado com recursos do FAR, PMCMV, pelo Faixa 1 - Patos/PB

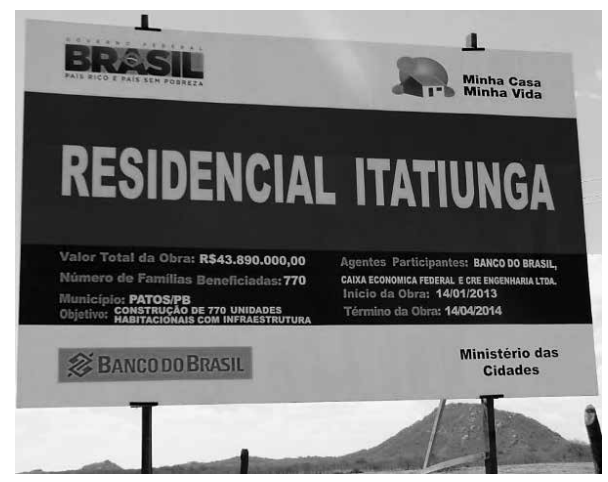

Figura 2 - Panfleto de lançamento do Loteamento Parque Itatiunga, março de 2014 - Patos/PB

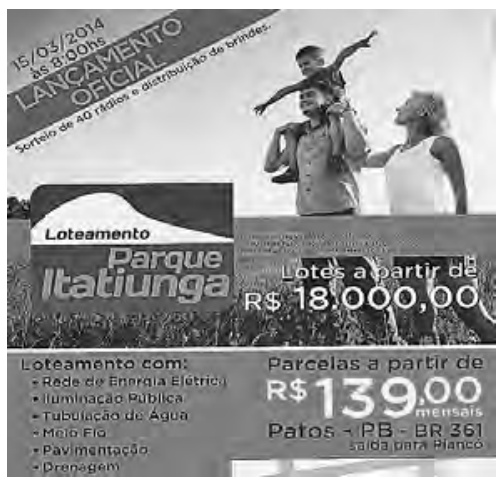

A partir das reflexóes de Smolka (1987), entendemos que essa é uma prática especulativa, comum na movimentação do capital incorporador que visa valorizar a terra. A valorização ocorre, inicialmente, com a transformação do uso da propriedade fundiária, do rural para o urbano. À medida que o empreendimento - no caso, o loteamento - é beneficiado com a adição dos equipamentos de infraestrutura básica, a tendência é agregar mais valor venal aos lotes.

Em relação aos conjuntos habitacionais operacionalizados pelo PMCMV, o "pacote" contratado pelo governo federal, em parceria com outros níveis de governo, inclui as obras de terraplenagem, a abertura das vias de circulação e de escoamento das águas pluviais, entre outras, bem com a implantação da infraestrutura básica (saneamento, abastecimento de água, eletrificação etc.) e de serviços comunitários (postos de saúde, escolas, segurança pública etc.).A implantação e/ou extensão desses equipamentos, obrigatórios para a habitabilidade do conjunto, torna-se atributo valorativo, utilizado pelo marketing de vendas de empreendimentos privados, tal como no panfleto recuperado pela figura 2. Nesse caso, o Estado contribui com a produção de externalidades que favoreceram o empreendedor, desonerando-o, por exemplo, do uso de parte de seu capital de incorporação, reservado à adequação 
de tais equipamentos em seu empreendimento. ${ }^{9}$ Essa é uma das formas dos incorporadores controlarem a valorização dos lotes para obter mais renda fundiária e mais ganhos imobiliários.

$\mathrm{Na}$ primeira etapa, o projeto Residencial Itatiunga submetido ao PMCMV compreendia uma área total de 204.642,60 $\mathrm{m}^{2}$, da qual $61,1 \%$ era destinada a lotes habitáveis, com apenas $4,8 \%$ de área verde. De acordo com o seu memorial descritivo, nessa etapa estava prevista a implantação de cinco equipamentos públicos, distribuídos em pouco mais de cinco mil metros quadrados, dentre eles: uma escola, com seis salas de aula; uma unidade básica de saúde; e uma estação de tratamento de esgoto pré-fabricada. Os dois primeiros foram implantados com recursos do Fundo de Amparo ao Trabalhador (FAT) sob a gestão do Banco Nacional do Desenvolvimento (BNDES) e do Ministério Desenvolvimento, Indústria e Comercio Exterior.

Segundo informação do representante da CRE Engenharia Ltda., construtora responsável pelas obras desse residencial, o projeto foi executado de acordo com o padrão normativo de especificação mínima exigido pelo Ministério das Cidades e fiscalizado pelo Banco do Brasil, instituição financeira gestora dos recursos. Porém, a despeito da rigidez dessa instituição sobre o cumprimento das normas técnicas e do prazo para a entrega, prevista para 2014, a entrega das casas aconteceu somente em 2016, depois de forte pressão das famílias beneficiadas.

Conforme o secretário de habitação da Prefeitura de Patos, o atraso da entrega do conjunto decorreu por alguns equipamentos previstos na Portaria n. ${ }^{\circ}$ 168/2013 não terem sido concluídos. Pela normativa, "as redes de energia elétrica e iluminação pública, o abastecimento de água potável e as soluçóes para o esgotamento sanitário deverão estar operantes até a data de entrega do empreendimento ou da respectiva etapa" (MCidades, 2013). Isso não ocorreu. As obras dos demais equipamentos básicos, como a escola e o posto de saúde, foram oficialmente anunciados em 2016, após a entrega das casas aos beneficiários.

Outro equipamento de infraestrutura básica reivindicado pelos moradores foi a conclusão da via de acesso que interliga o conjunto à BR-361, cujo trecho era carroçável e considerado por um entrevistado como "muito

${ }^{9}$ Cf. Lei n.o 9.785/99, a qual dispõe sobre alteraçóes na Lei n.o 6.766/79 de Parcelamento do Solo Urbano. 
ruim, cheio de buraco e sem iluminação pública" $\cdot{ }^{10}$ Segundo manifestou um morador, o conjunto ficou muito distante do centro da cidade, fato agravado pela falta de transporte público, o que dificultava o deslocamento das pessoas para terem acesso aos mais diferentes serviços. Assim relatou:

Aqui não é ruim, porque a casa é da gente, né? Mas está todo mundo abandonado, sabe? Até agora, não apareceu ninguém da prefeitura [...] tem lixo por todo canto e falta muita coisa ainda para a gente. [...] está difícil demais, para sair daqui para o centro [...] é tudo muito longe [...]. Quem tem moto, carro está bom, mas ficou longe de tudo mesmo. Tem gente que deixou ir para a escola porque não tem como ir, não tem como pagar o mototáxi. Eles também não querem fazer viagem de noite para cá. É muito perigoso [...] tem outro problema, falta a gente receber os contratos [...]. Sim, tem mais, o papel da luz está vindo alto demais, a gente não sabe por que a luz é cara aqui. Eles não tão respeitando ninguém aqui. [...] o povo tá se organizando se vem alguma coisa pra gente. ${ }^{11}$

Esse depoimento é emblemático porque ratifica o quanto persistem historicamente as velhas práticas que revelam a reprodução do negligenciamento por parte do poder público com as condiçóes de infraestrutura da habitação de interesse social, em diferentes esferas territoriais do nosso país. Reativa também os velhos dilemas e as contradiçôes que assinalam o descompasso entre a política habitacional e a política de urbanização.

Conforme o croqui de localização geográfica do residencial, presente o projeto arquitetônico, as distâncias em relação a importantes equipamentos de serviços e espaços públicos e de consumo, como a prefeitura, os correios, o hospital regional, o mercado público ou a catedral, situados na área mais central da cidade, são realmente consideráveis. No cotidiano dos moradores, o deslocamento onera o orçamento familiar e estabelece um custo relativo ao tempo-espaço necessário para que seja exercido, especialmente pela inexistência de transporte público regular.

No que respeita às distâncias, fica o destaque em relação ao centro da cidade. Quando o Estado aprova projetos de grandes conjuntos habitacionais

\footnotetext{
${ }^{10}$ Informação direta obtida por meio de conversa informal com os moradores durante trabalho de campo realizado em julho de 2016.

${ }^{11}$ Cf. nota anterior.
} 
voltados a interesse social, sendo necessária a obtenção de maiores porções de glebas rurais, a terra disponibilizada, em geral, encontra-se bem afastada da área central da cidade, fora dos limites do perímetro urbano, comumente desprovida de qualquer infraestrutura básica.

Além das distâncias dificultarem o acesso de grande parte dos moradores do conjunto a esses serviços, a inexistência de linhas de transporte público, interligando o conjunto ao centro, onde estáo localizados a maioria dos equipamentos básicos, constitui-se em um outro problema. O deslocamento dos moradores é feito essencialmente por serviços de moto-táxi, ofertados sobretudo no turno diurno.

Assim, entendemos que, para que os moradores de conjuntos habitacionais obtenham o mínimo possível para torná-las urbanizadas e habitáveis, é necessário formar organizaçôes sociais e de mobilização, cuja pauta reivindicatória exerça forte pressão sobre o poder público. Com efeito, a mobilidade da sociedade, em diferentes áreas da cidade, ao reivindicar o atendimento de suas demandas específicas, tensiona um movimento de forças entre os moradores organizados e o poder público, bem como entre os distintos movimentos, diferentemente espacializados na cidade.

Registramos situação semelhante no Vista da Serra I e II, embora os problemas quanto ao acesso ao centro tenham sido pouco referidos. Esses conjuntos fazem parte da incorporação do Loteamento Empresarial Hardman Cavalcante, no Bairro Monte Castelo, localizado na zona sul da cidade, às margens do Rio da Farinha, em terras desmembradas do antigo Sítio Mutuca/Frei Manoel. A incorporação do loteamento também foi feita por uma construtora com sede em João Pessoa, a JGA Engenharia Ltda. No total, foram abertos 286 lotes, com uma área média de $200 \mathrm{~m}^{2}$, abrangendo 10 , 5 ha.

Após a incorporação, em 2012, foram contratadas 136 unidades habitacionais pelo PMCMV para edificar o Residencial Vista da Serra I, e em 2013, o Residencial Vista da Serra II, com 106. Portanto, 245 habitaçóes, ambos em parceria com o governo do Estado, por meio da Companhia Estadual de Habitação Popular (CEHAP-PB), com recursos do FAR sob a gestão da CEF como instituição financeira. As duas etapas somaram um investimento de 6,3 milhóes de reais.

Para descrever o processo de incorporação daquele loteamento, reiteramos os escritos de Lucena (2014), ao esclarecer que 
o proprietário da construtora já possuía o terreno, que foi adquirido em um momento anterior. Segundo o engenheiro responsável pela obra, o processo de loteamento ocorreu da seguinte forma: foi realizado um primeiro loteamento, no qual o proprietário desmembrou alguns lotes e os deixou como suas propriedades; em seguida, juntou os demais terrenos novamente e loteou pela segunda vez, agora com as características mínimas exigidas pela CEF para aprovar o projeto através do PMCMV. Quando as unidades do RSV I estavam praticamente prontas, foi promovida a venda dos lotes desmembrados daquele primeiro loteamento, cujos preços dos terrenos foram estabelecidos em torno de R\$18.000,00. (Lucena, 2014, p. 156).

Com base na autora, confirmamos a construção do conjunto habitacional em duas etapas, sob a mesma lógica especulativa descrita para o Itatiunga. No intervalo entre a conclusão da primeira etapa e o início das obras da segunda, quando foram enunciados e/ou instalados os equipamentos básicos pelo Estado, o incorporador lançou no mercado imobiliário os lotes de sua propriedade, valorizados pela infraestrutura pública. Desse modo, o capital do incorporador tende a se expandir com a ampliação da base de incidência das rendas, metamorfoseando o ganho imobiliário do proprietário do loteamento e dos adquirentes futuros.

Assim, à maneira da explicação de Smolka (1987, p. 53), "trata-se aqui de criação de vantagens locacionais, pertinentes não propriamente a diferenças de produtividade na produção de moradia, mas sim às condiçóes de criação do solo de características dadas, como a acessibilidade”. Da mesma forma, os equipamentos básicos implantados geram externalidades internalizáveis apropriadas pelo incorporador para a criação de rendas diferenciais.

No caso desse loteamento e, por conseguinte, dos conjuntos habitacionais Vista da Serra I e II, outra particularidade que merece menção são as condiçôes ambientais. Como representado na planta arquitetônica, do total loteado, 1,7ha corresponde a três áreas de preservação ambiental, sendo uma delas relativa ao remanescente das margens rio da Farinha, afluente do rio Espinharas, que dista uma média de 40 metros dos quarteiróes situados a leste do conjunto. Conforme vemos nas imagens do Google Earth, os lotes destinados ao conjunto estão situados muito próximos ao curso hídrico, o que torna a área propícia a alagamentos em períodos de chuvas (figura 3). 
A despeito da existência de problemas ambientais, de infraestrutura e de serviços existentes no Conjunto Vista da Serra e nas imediaçôes, na época do lançamento do Loteamento Hardman Cavalcante, em 2010, depois de concluída a primeira etapa do conjunto, o marketing de venda anunciava, antecipadamente, a implantação de equipamentos básicos, de áreas para comércio e uma rede hoteleira não especificada no projeto arquitetônico. Entretanto, como vimos in loco, e pelo que foi noticiado em mídias digitais, ${ }^{12}$ as condiçóes de habitabilidade do Conjunto Vista da Serra não estão em consonância com o que foi propalado no processo de vendas dos lotes.

Figura 03 - Usos e apropriaçôes no Loteamento Hardman Cavalcante, Bairro Monte Castelo - Patos/PB

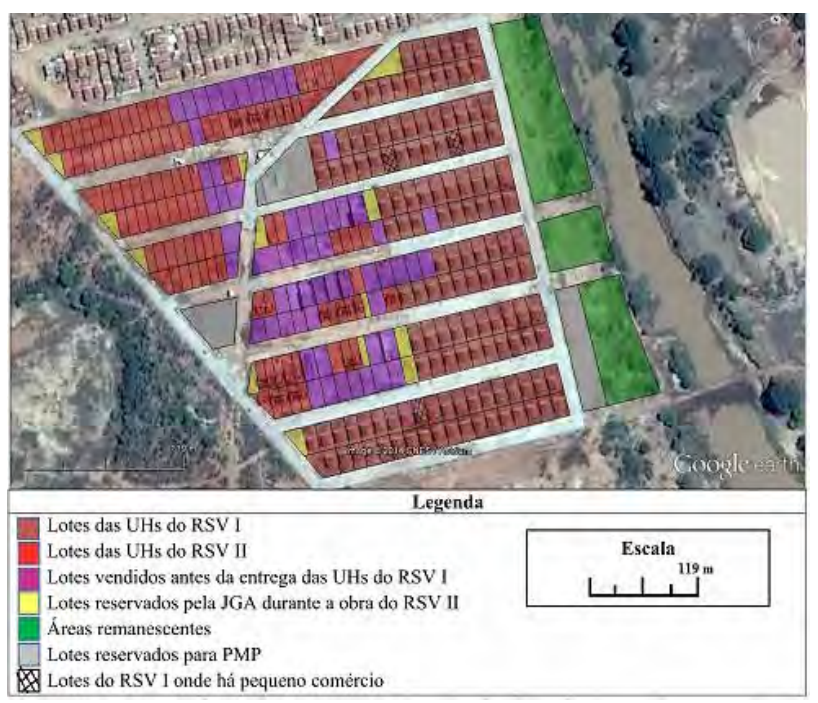

Fonte: Lucena, 2014, p.179.

Pelo exposto, o problema da habitação popular assume similaridade em diferentes escalas de tempo e de espaço, cujas condiçóes de habitabilidade são negligenciadas pelo poder público, em especial quando se trata da Habitação de Interesse Social (HIS). Contudo, ao que parece, sem a intervenção do Estado, nada de efetivo se realiza para saná-lo. As famílias de baixa renda se submetem a viver em meio à precariedade dos conjuntos habitacionais por

${ }^{12}$ Cf. vídeo: "Morador do conjunto vista serra, Monte Castelo, Patos, fala dos problemas". Disponível em: https:/www.youtube.com/watch?v=26hoZqIl3-I. Acesso em: mar. 2017. 
suas condiçôes de renda, ante a impossibilidade de escolher onde morar ou como morar. Ou seja, historicamente, como enfatiza Hall (2002, p. 25), as famílias pobres estão sujeitas a "um sistema de governo local incompetente e amiúde corrupto, inepto no manejo dos pobres".

$\mathrm{Na}$ seção seguinte, analisaremos a produção habitacional das cidades de Patos e de Cajazeiras voltadas para as modalidades de financiamento nas faixas II e III, contratadas pelo FGTS.

\section{Produçáo habitacional do PMCMV financiada pelo FGTS em Patos e em Cajazeiras}

No âmbito do SNH, as contrataçóes para a produção de novas unidades habitacionais nas faixas 2 e 3 são subvencionadas por meio de créditos habitacionais, especialmente oriundos do FGTS. Essas modalidades atendem às famílias inseridas nas linhas de rendimento que variam de mais de três a dez salários mínimos que, grosso modo, constituem a segunda grande base da demanda habitacional. Lembramos ao leitor que, no caso dos financiamentos com recursos do FGTS, dentro dessas duas faixas, o governo federal criou o PMCMV-Habitacional, que funciona a partir de duas linhas de financiamento para o comprador da habitação - pessoa física -, como ocorre na Faixa 1, na qual as contrataçóes são realizadas por meio do PMCMV-Empresa.

Como vimos na seção anterior, no que concerne à Faixa 1, a cidade de Patos foi beneficiada com 1.015 unidades financiadas pelo FAR. Se somarmos todos os financiamentos, temos 2.772 contrataçóes operacionalizadas pelo PMCMV, com mais de $63 \%$ do total da produção habitacional voltados a famílias com rendimento acima de três salários mínimos. A questão é que esse segmento apresentou uma demanda habitacional menor (cerca de $20 \%$, relativos a 876 novas moradias). Já o déficit habitacional correspondente àquela faixa, também para o ano de 2010, equivalia a 80\% (3.521 novas moradias), segundo a Fundação João Pinheiro (FJP).

O gráfico 2 foi elaborado com base na planilha de produção habitacional fornecida pelo Ministério das Cidades, entre o ano de 2009 até o mês de outubro de 2015. Nele, vemos que, nas cidades de Patos e Cajazeiras, o PMCMV contratou 3.392 unidades habitacionais financiadas pelo FGTS. Dessas contrataçóes, quase $52 \%$ foram efetuadas em Patos, sendo as demais em Cajazeiras. 
Isso significa que não houve equidade na distribuição dos recursos públicos subvencionados pelo PMCMV. Essa problemática agrava-se ainda mais em Cajazeiras, como sabemos, pois as famílias mais pobres sequer foram comtempladas na cidade, em que o déficit habitacional urbano apontava uma carência de 1.850 novas moradias, das quais 1.442 envolvia esse segmento (similarmente, quase $80 \%$ ).

Gráfico 2 - Número de unidades habitacionais contratadas pelo PMCMV, nas modalidades das Faixas 2 e 3, em Patos e Cajazeiras/PB - 2009 a 2015

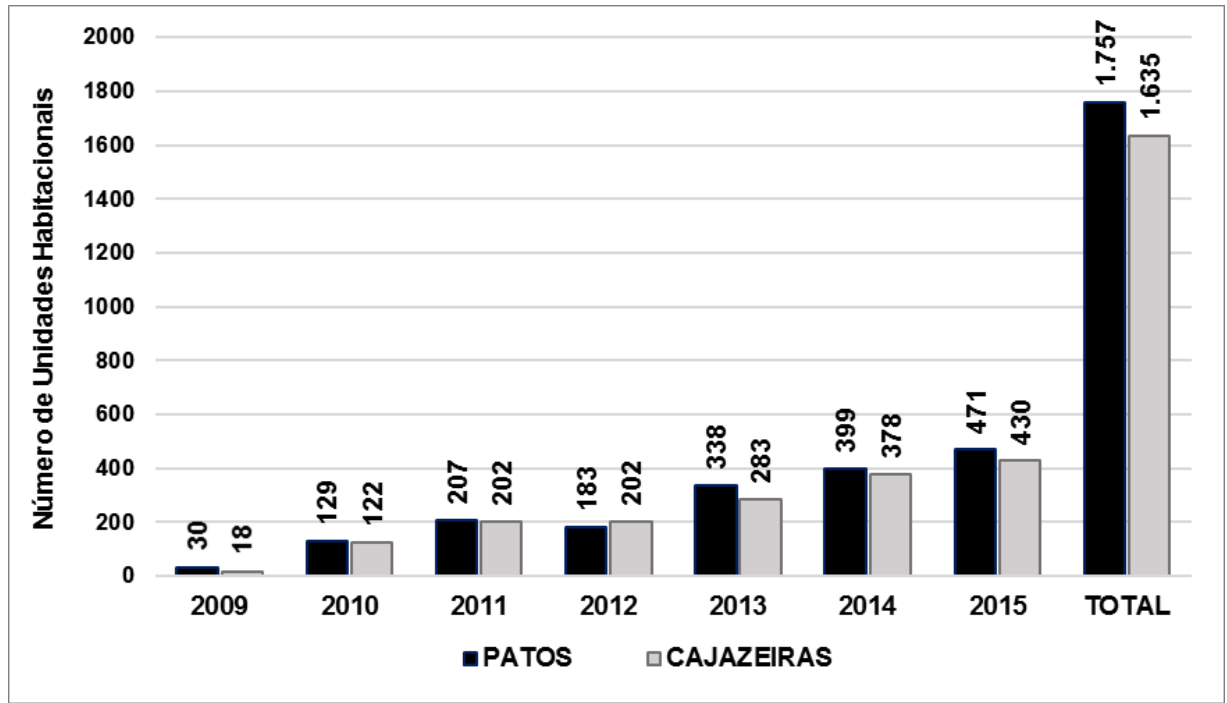

Fonte: Elaborado por Luciana M. de Araújo (2017), a partir de relatórios da SNH/MCidades (2016)

Os valores investidos nas duas cidades, vistos por faixa, são outra maneira de apontar o descompasso no curso dos financiamentos viabilizados pelo PMCMV. Em Patos, não obstante a construção das 1.015 novas moradias em três conjuntos habitacionais pelo PMCMV, a Faixa 1 absorveu apenas $20 \%$ do total de créditos, um dado que é sequer existente no que diz respeito à cidade de Cajazeiras.

Diferentemente da modalidade Faixa 1, o exame das planilhas do PMCMV, fornecidas pela Secretaria Nacional da Habitação do Ministério das Cidades, revelou que o valor das contrataçóes para a produção de habitação pela Faixa 2 na cidade de Patos e de Cajazeiras, absorveu o correspondente a $77 \%$ e $98 \%$, respectivamente, relativas ao total do valor contratado entre 
os anos de 2009 e 2015. Quanto ao valor da contratação por unidade habitacional, ainda relativo à Faixa 2, constatamos uma pequena diferença para menos na cidade de Cajazeiras (média de $\mathrm{R} \$ 97 \mathrm{mil} / \mathrm{unid}$.), comparado ao valor da unidade contratada em Patos (média R\$101 mil/unid.) (Gráfico 3).

No cálculo geral, a proporção dos investimentos em relação ao número de unidades habitacionais construídas chega à média de $\mathrm{R} \$ 110$ mil, abaixo do limite normatizado pelo Ministério das Cidades, fixado em até $150 \mathrm{mil}$ reais para grande parte do país, inclusive para o Nordeste. ${ }^{13}$

Gráfico 3 - Valores contratados pelo PMCMV, por modalidade de faixa, entre 2009 e 2015 - Cajazeiras e Patos/PB

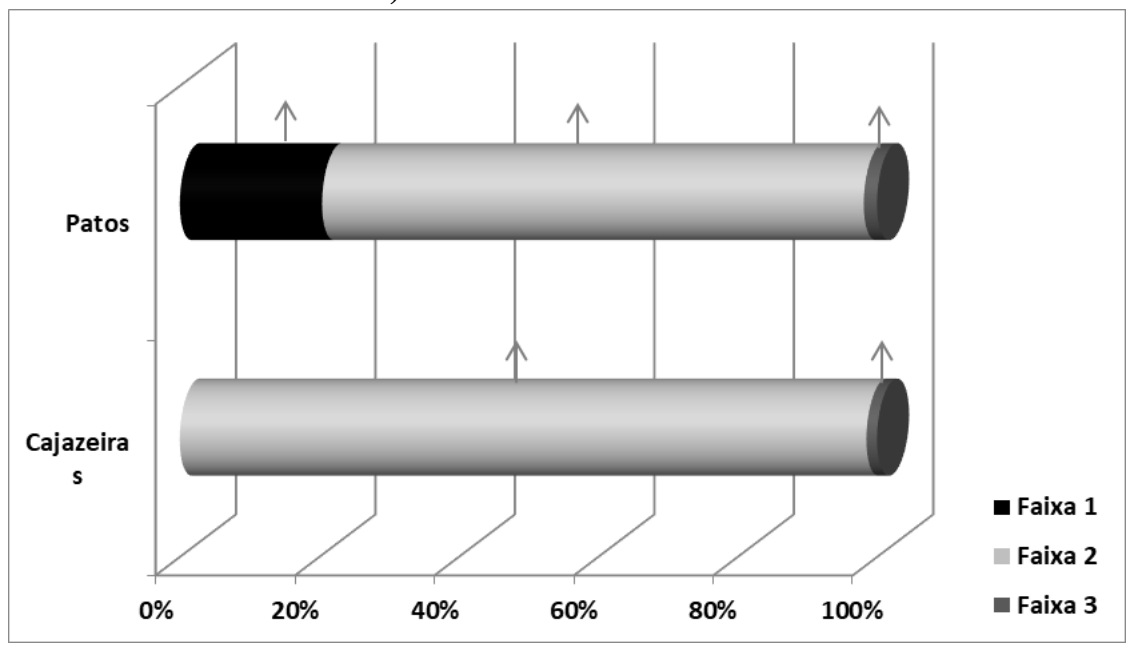

Fonte: Elaborado por Luciana M. de Araújo (2017), a partir de relatórios da SNH/MCidades (2016).

No tocante ao total de habitaçóes produzidas pelo PMCMV, a Faixa 2 é responsável pela contratação de 76,9\% dessa produção. Isso reforça a compreensão de que a expansão desse sistema de financiamento tem como característica o modelo de subsídios para a demanda, que direciona a disponibilização direta de recursos públicos aos compradores de imóveis. Como admite Rolnik: "o raciocínio por trás dos programas de subsídios para a demanda é o de que mesmo famílias de menor renda poderão mobilizar suas poupanças para financiar suas moradias no livre mercado" (Rolnik, 2015, p. 111).

${ }^{13}$ Esses valores são diferenciados para as regiōes metropolitanas de São Paulo, Rio de Janeiro e Distrito Federal, fixado em até 170 mil reais. 
Para corroborar o impacto do PMCMV sobre o setor imobiliário, sobretudo no que concerne à construção civil exclusivamente dirigida à produção residencial, elaboramos a tabela 2. Nela, temos a indicação entre todas as Anotaçóes de Responsabilidade Técnica (ART) emitidas pelo Conselho Regional de Engenharia e Agronomia (CREA/PB) nas duas cidades e os dados relativos aos imóveis produzidos pelo programa, sendo eles correlacionados. Isso nos remete ao incremento verificável nessa produção a partir de 2010, logo depois da implementação dessa política habitacional.

Tabela 2 - Total de emissão de anotaçóes de responsabilidade técnica (ART) e total de unidades habitacionais contratadas pelo PMCMV nas Faixas 2 e 3, em Cajazeiras e Patos/PB - 2009 a 2015.

\begin{tabular}{l|c|c|c|c|c|c}
\hline \multirow{2}{*}{ Ano } & \multicolumn{3}{|c|}{ Cajazeiras } & \multicolumn{3}{c}{ Patos } \\
\cline { 2 - 7 } & $\begin{array}{c}\text { ART } \\
\text { Emitidas }\end{array}$ & $\begin{array}{c}\text { Unidades } \\
\text { Produzidas } \\
(\text { PMCMV) }\end{array}$ & $\begin{array}{c}\text { Produçáo } \\
\text { PMCMV/ } \\
\text { ART } \\
(\%)\end{array}$ & $\begin{array}{c}\text { ART } \\
\text { Emitidas }\end{array}$ & $\begin{array}{c}\text { Unidades } \\
\text { Produzidas } \\
(\text { PMCMV) }\end{array}$ & $\begin{array}{c}\text { Produçáo } \\
\text { PMCMV/ } \\
\text { ART } \\
(\%)\end{array}$ \\
\hline $\mathbf{2 0 0 9}$ & 177 & 18 & 10.1 & 107 & 30 & 28,0 \\
\hline $\mathbf{2 0 1 0}$ & 282 & 122 & 43,2 & 187 & 129 & 68,9 \\
\hline $\mathbf{2 0 1 1}$ & 379 & 202 & 53,2 & 202 & 207 & 102,4 \\
\hline $\mathbf{2 0 1 2}$ & 326 & 202 & 61,9 & 398 & 183 & 45,9 \\
\hline $\mathbf{2 0 1 3}$ & 370 & 283 & 76,4 & 460 & 338 & 73,4 \\
\hline $\mathbf{2 0 1 4}$ & 599 & 378 & 63,1 & 366 & 399 & 109,0 \\
\hline $\mathbf{2 0 1 5}$ & 575 & 430 & 74,7 & 390 & 471 & 120,7 \\
\hline Total & 2.708 & 1.635 & 60,3 & 2.110 & 1.757 & 83,2 \\
\hline
\end{tabular}

Fonte: Elaborada por Luciana M. Araújo (2017), com base em dados do CREA/PB e da SNH/MCidades (2016)

Ainda sobre a tabela 2, destacamos que nos anos de 2011, 2014 e 2015, o número de unidades habitacionais contratadas pelo PMCMV superou o de ART. Isso justifica-se pela compra de imóveis produzidos anteriormente, pois havia um grande estoque de imóveis para comercialização em seu mercado imobiliário, conforme informado pelo presidente do Conselho Regional de Corretores de Imóveis (CRECI). Os indicadores consolidam o lugar determinante do Estado naquele incremento da produção habitacional. 
Desse modo, no contexto da atual PNH, o PMCMV foi fundamental para a garantia do acesso ao crédito habitacional, subvencionando a aquisição da casa própria realizada por milhares de famílias com rendimento baixo e médio. Todavia, no tocante às condiçóes de habitabilidade do entorno e das edificaçôes em si, muito há para se analisar e discutir. Afinal, como sentenciam Rolnik e Nakano (2009), a despeito dos instrumentos normativos de controle sobre a produção de habitação de interesse social ou de mercado, ambas continuam sendo realizadas em áreas de expansão urbana sem adequaçôes satisfatórias de habitabilidade, marcadas por infraestruturas e acessibilidades precárias e/ou inexistentes.

\section{Consideraçóes finais}

Como constatamos, a partir da instituição do PMCMV, houve um incremento da produção da habitação de interesse social, porém, sobremaneira, grande parte dessa produção foi destinada à habitação social de mercado, o que favoreceu os promotores privados da produção imobiliária. Os dados apresentados atestam a viabilidade econômica dessa produção e reforçam o viés empresarial que o PMCMV assumiu desde a sua implantação, em 2009, ao atender muito mais à demanda habitacional de mercado do que a carência de moradias para as famílias mais pobres, carência essa trazida nos relatórios do déficit habitacional.

Portanto, entendemos que a PNH segue um curso de práticas que deixam lacunas na qualidade da política pública voltada à habitação. Essas práticas são remissivas a um modelo de fragmentação da cidade, repartida em espaços desiguais, em que a precariedade urbana e ambiental é reproduzida, tensionadas por conflitos de interesses entre os distintos agentes imobiliários e os moradores de conjuntos habitacionais.

De modo recorrente, percebemos o discurso reducionista e até mesmo demagógico de representantes do poder público quanto à realizaçáo do "sonho da casa própria” por famílias de baixa renda. Um discurso em que impossibilidade socioeconômica dessas famílias quanto à escolha e à qualidade de onde morar na cidade é encoberta pelo "sonho" realizado. À maneira de Bonduki (1998), mitifica-se essa realização, diluindo-se as precariedades que a perpassam. 
Assim, o Estado, como agente imobiliário ou como gestão pública, não tem desempenhado efetivamente o seu papel de fiscalizador dos processos de apropriaçáo e de uso do solo urbano pelos agentes privados, nem de produzir habitação de interesse social para a população com menos poder aquisitivo, diretamente excluída dos processos decisórios sobre essa produçáo. Devido à falta de um planejamento comprometido com o desenvolvimento urbano, o poder público não se interpôs à celeridade da expansão urbana, que aconteceu independentemente da capacidade da gestão e da disponibilidade das receitas orçamentárias das prefeituras municipais destinadas aos programas urbanos.

Como admite Melazzo (2013) ao discutir a produção habitacional pelo PMCMV, é inquestionável que a nova PNH repercutiu em mudanças substanciais na forma de produção e de apropriação da cidade. Porém, tais mudanças acentuaram as desigualdades inerentes à expansão urbana, bem como os conflitos entre os diferentes agentes produtores do espaço urbano.

Por fim, à cidade imprime-se uma celeridade na sua expansão territorial, com repercussóes diferenciadas sobre a sociedade local, com evidente favorecimento do setor imobiliário como um todo e do mercado de terras, potencializando a renda delas advinda, a partir do expressivo aumento de lotes urbanizados disponibilizados para o mercado.

\section{Referências}

BONDUKI, Nabil. As origens da habitação social no Brasil: arquitetura moderna, Lei do Inquilinato e difusão da casa própria. São Paulo: Estação Liberdade, FAPESP, 1998. 343 p. BRASIL. "Política Nacional de Habitação". In: Cadernos Mcidades Habitação. Ministério das Cidades, 2004. Disponível em: http://www.cidades.gov.br/images/stories/ArquivosSNH/ ArquivosPDF/4PoliticaNacionalHabitacao.pdf. Acesso em: dez. 2009.

. Presidência da República. "Decreto n. ${ }^{\circ}$ 025/2007 de 22 de janeiro de 2007. Institui o Programa de Aceleração do Crescimento - PAC, o seu Comitê Gestor e dá outras providências". Diário Oficial [da] República Federativa do Brasil, Brasília, DF. Disponível em: http://www.planalto.gov.br/ccivil_03/_Ato2007-2010/2007/Decreto/D6025compilado. htm. Acesso em: set. de 2010.

. Presidência da República. Lei n. ${ }^{\circ} 11.977$, de 7 de julho de 2009. Dispóe sobre o Programa Minha Casa, Minha Vida - PMCMV e a regularizaçấo fundiária de assentamentos localizados em áreas urbanas; altera o Decreto-Lei $n^{\circ} 3.365$, de 21 de junho de 1941, as Leis $n^{o s} 4.380$, de 21 de agosto de 1964, 6.015, de 31 de dezembro de 1973, 8.036, de 11 de maio de 1990, e 10.257, de 10 de julho de 2001, e a Medida Provisória no 2.197-43, de 24 
de agosto de 2001; e dá outras providências. Disponível em: https://www.planalto.gov.br/ ccivil_03/_ato2007-2010/2009/lei/111977.htm. Acesso em: jan. 2013.

. Portal Minha Casa, Minha Vida. Disponível em: http://www.minhacasaminhavida. gov.br/. Acesso em: jun., 2014

PAC. Programa de Aceleração do Crescimento. $1^{\circ}$ Balanço, 2015. Disponível em: http://www.pac.gov.br/pub/up/relatorio/ccedac8ebd8bfe1 fefc25c0e4e4e8c0c.pdf Acesso em: maio 2015.

CANO, W. Reflexöes sobre o papel do capital mercantil na questäo regional e urbana do Brasil. v. 177. Campinas: IE/Unicamp, 2010.

CAIXA ECONÔMICA FEDERAL. Circular Caixa no 681 de 10 de junho de 2015. Define critérios e procedimentos operacionais para aplicação das diretrizes da Politica Socioambiental do Fundo de Garantia do Tempo de Serviço - FGTS, nas áreas de habitação, saneamento e infraestrutura. Disponível em: http://www.caixa.gov.br/Downloads/FGTS-circulares-caixa-fgts2015/CircularCAIXA_2015_681.pdf

FIX, Mariana. Financeirização e Transformaçōes Recentes no Circuito Imobiliário no Brasil. (Tese). Campinas: UNICAMP, 2011.

FJP. Fundação João Pinheiro. Déficit Habitacional no Brasil, 2000. . Déficit Habitacional no Brasil, 2010.

HALL, Peter. "A Cidade da Noite Apavorante. Reaçôes à cidade encortiçada do século XIX: Londres, Paris, Berlim e Nova York (1880 a 1900)”. In: Cidades do Amanhã. São Paulo: Perspectiva, 2002. pp. 19-53.

IBGE. Divisão do Brasil em Mesorregiōes e Microrregiōes geográficas, 1990. Disponível em: http://www.biblioteca.ibge.gov.br/visualizacao/monografias/GEBIS\%20-\%20RJ/DRB/ Divisao\%20regional_v01.pdf. Acesso em: abr. 2013.

. Divisão Urbano Regional, 2013. Disponível em: ftp://geoftp.ibge.gov.br/organizacao_do_territorio/divisao_regional/divisao_urbano_regional/documentacao/divisao_urbano_regional_apresentacao_do_trabalho.pdf. Acesso em: mar. 2015.

LUCENA, Wilma G. A produção do espaço urbano da cidade de Patos/PB: do BNH ao Programa Minha Casa, Minha Vida. (Dissertação). João Pessoa: UFPB, 2014.

MARICATO, Ermínia. Para entender a crise urbana. São Paulo: Expressão Popular, 2015.

MELAZZO, Everaldo S. "Dinâmica Imobiliária e Processos de Estruturação Intra-Urbana em Cidades de Porte Médio: hipóteses e propostas de Trabalho". In: Encontro Nacional de Geógrafos, n. 16, 2010, Porto Alegre. Anais Eletrônico. Disponível em: file:///D:/ Downloads/T0026\%20-\%20EVERALDO\%20MELAZZO.pdf. Acesso em: mai. 2013. ROLNIK, Raquel. Guerra dos Lugares. A Colonização da Terra e da Moradia na Era das Finanças. $1^{\text {a }}$ ed. São Paulo: Boitempo, 2015.

e NAKANO, Kazuo. "As armadilhas do pacote habitacional". Le monde diplomatique Brasil, 2009, 5 mar. 2009.

SHIMBO, Lúcia Z. Habitação Social, Habitação de Mercado: a Confluência entre Estado, Empresas Construtoras e Capital Financeiro. (Tese). São Carlos (SP): USP, 2010.

SMOLKA, Martin O. "O capital incorporador e seus movimentos de valorizaçáo". In: Cadernos IPPUR/UFRJ, ano II, n. 1, jan./abr. Rio de Janeiro: UFRJ, 1987. pp. 41-78. 
TOPALOV, C. "Análise do ciclo de reprodução do capital investido na produção da indústria da construçáo civil. Capital e propriedade fundiária”. In: FORTI, R. (org.) Marxismo e Urbanismo Capitalista: textos críticos. São Paulo: LECH, 1979a.

C. La Urbanización Capitalista. Algunos Elementos para su Análisis. México: Edicol, 1979b. Disponível em: http://institutodeestudiosurbanos.info/dmdocuments/cendocieu/ Especializacion_Mercados/Documentos_Cursos/Urbanizacion_Capitalista-Topalov_ Christian-1979.pdf. Acesso em: jan. 2016. 